\title{
De nós para você para mim: a co-construção da identidade nas interações iniciais*
}

\author{
Rod Parker-Rees**
}

\section{Resumo}

Desde uma perspectiva histórico-cultural, a relação entre os processos interpsíquicos de interação social "pública" e os processos intrapsíquicos de pensamento "privado" é complexa e recíproca. Embora se possa dizer que a identidade emerge a partir de um "nós" primário, também é possível argumentar que só somos capazes de desenvolver a autoconsciência porque internalizamos formas de interação que são inicialmente vividas entre as pessoas. Neste artigo, será considerada como a construção compartilhada da identidade pode ser entendida em termos de uma habilidade em desenvolvimento para participar do fluxo de informaçóes oferecidas por interaçóes sociais. Argumenta-se que as interaçôes sociais fornecem oportunidades para aprender muito mais sobre outras pessoas (e sobre nós mesmos) do que é acessível à nossa percepção consciente.

Palavras-chave: Infância. Identidade. Internalização.

* Tradução de Suely Amaral Mello, Professora na Universidade Estadual Paulista Júlio de Mesquita Filho (UNESP), campus Marília. Revisão técnica de Maria Auxiliadora Soares de Farias.

** Professor Associado em Estudos da Primeira Infância em Plymouth Institute of Education (Faculty of Arts \& Humanities), Reino Unido. 
Há muito tempo já se aceita a ideia de que as crianças não nascem com uma identidade pessoal pronta. A consciência percebida de um sentido de si específico e pessoal deve ser construída, ou co-construída, com a ajuda da família e da comunidade imediata. Neste artigo me proponho a explorar as primeiras fases desse processo, no primeiro ano de vida, a partir de uma perspectiva histórico-cultural. Vygotsky (1998) argumentou que o nosso sentido pessoal de si emerge de um estado inicial de coconsciência, Пра мы ${ }^{1}$, que é significativamente diferente da nossa consciência posterior de um "nós" coletivo, feita de vários indivíduos separados:

Em primeiro lugar, o que surge na consciência da criança pode ser chamado mais precisamente como "Ur-Wir", isto é, "protonós". Essa consciência inicial de comunalidade mental que precede o desenvolvimento da consciência de sua própria personalidade (isto é, a consciência de um "eu" diferenciado e separado) é uma consciência de "nós", mas não uma consciência complexa de "nós", que inclui o "eu" [...]. (VYGOTSKY, 1998, p. 232).

Vygotsky (1998) entendia desenvolvimento como mudanças nas relaçôes entre as formas externas (interpessoais) e as formas internas (intrapessoais) da atividade social. Vou argumentar que esta ênfase no fluxo de interação, tanto entre indivíduos como internamente a eles, pode oferecer uma perspectiva mais vantajosa acerca do desenvolvimento inicial da identidade social que modelos mais individuais do tipo "enviar e receber" que enfatizam a posse pessoal de declaraçôes ou atos. Nossas primeiras experiências sociais são de participação direta, consubstanciadas no fluxo de intersubjetividade, no nível do proto-nós, e nós construímos o nosso eu a partir desse envolvimento: "A subjetividade nasce da familiaridade da intersubjetividade" (ZEEDYK, 2006, p. 326). A natureza da relaçấo entre intersubjetividade e subjetividade e entre aquilo que nós pensamos como "eu" e "não eu" está longe de ser simples.

John Shotter (2014) desenvolveu o conceito de "corte agencial" de Karen Barad para argumentar que a nossa distinção entre interação, fluxo de informaçóes entre os indivíduos e ação interna - o fluxo de informaçóes dentro de um indivíduo - é enganosa e simplista. Nossas decisōes sobre onde fazer "cortes agenciais" entre o que percebemos como "eu" - o agente subjetivo - e "você" ou "algo" são flexíveis, dependentes do contexto e culturalmente condicionadas. $\mathrm{O}$ autor usa o conhecido exemplo de uma pessoa segurando uma bengala. $\mathrm{O}$ corte entre o agente e o objeto pode ser entre a pessoa e a bengala, como quando a bengala em si é o foco de atençáo, ou pode ser entre a pessoa com a bengala e o chão que a bengala toca, como quando a bengala está sendo usada 
como um instrumento para explorar o ambiente. De forma semelhante, poderíamos substituir a bengala pela internet, que pode ficar fora ou dentro de nosso "corte agencial" dependendo se estamos explorando a internet ou usando-a como ferramenta para explorar outra coisa. Também poderíamos substituir a bengala por outra pessoa e considerar como as crianças aprendem a pensar com outras pessoas e, depois, a pensar sobre os outros e sobre si mesmas.

Como Shotter (2014) reconhece onde e como se faz o "corte" - entre "nós" e "eu" ou entre o grupo social ao qual nós pertencemos e a identidade privada que nos diferencia dos outros do grupo - é diferente em diferentes culturas e em diferentes pontos da história de qualquer cultura. Norbert Elias (1978) argumentou que o "processo civilizatório" resultou no encolhimento do grupo social que define a nossa identidade adulta - da tribo ou clã à família ampla, em seguida, à família nuclear - um processo que continua à medida que aprendemos a dissociar o nosso "eu" do nosso corpo e, mais recentemente, até mesmo de partes inconscientes do nosso processamento mental ("meu cérebro me fez fazer isso").

Melvin Konner (2010) forneceu um relato ricamente detalhado da evolução da infância na qual ele mostra como sociedades caçadoras-coletoras e comunidades agrícolas mais assentadas criam condiçóes sociais e expectativas diferentes para formar os filhos para os papéis sociais que vão herdar. $\mathrm{O}$ autor argumenta que "a adaptação" ou pertencimento são mais valorizados nos grupos comunitários fortemente integrados de culturas nômades caçadoras-coletoras e que a interação social nesses grupos é caracterizada por níveis mais elevados de brincadeiras e menores níveis de regulação autoritária do que as comunidades assentadas, baseadas na propriedade, nas quais "destacar-se" é mais valorizado.

Em um artigo recente sobre um estudo comparativo entre as práticas parentais de mães alemãs e Nso (Camarōes), Kärtner, Holodynski e Wörmann (2013) basearamse no modelo de internalizaçáo do desenvolvimento emocional construído por Holodynski e Freidlmeier (2006) para sugerir que genitores desenvolvem "etnoteorias" que são influenciadas por um "meio cultural" particular que, por sua vez, influencia suas práticas parentais. Este "lugar" de influências culturais ecoa no modelo ecológico de Bronfenbrenner (1979), que mapeia as relações entre micro, meso e macrossistemas e também o modelo de Vygotsky (1997) de níveis intrapessoal, interpessoal e de interação sócio-histórica. As mães alemãs, vivendo em uma sociedade que incentiva a autonomia e o desenvolvimento de uma identidade própria, valorizaram interaçóes que incentivam o aparecimento da afetividade e atribuíram grande significado aos sorrisos sociais de seus filhos, porque estes indicam o momento em que a criança passa a ser vista "como uma pessoa com características singulares que reconhece sua mãe como um 
indivíduo específico" (KÄRTNER; HOLODYNSKI; WÖRMANN, 2013, p. 89). As mães Nso, no entanto, como as mães Gusii estudadas por Levine et al. (1994), viviam em uma sociedade que valorizava as relaçôes, obrigaçóes e responsabilidades sociais mais do que expressóes assertivas de individualidade - adaptar-se mais que destacar-se. Essas mães estavam mais preocupadas em acalmar e tranquilizar seus filhos do que em estimular-lhes e deram menos importância para os primeiros sorrisos sociais da criança.

Ao focar seu estudo sobre interação face a face e sorrisos sociais, Kärtner, Holodynski e Wörmann (2013) podem ter ignorado as formas mais contínuas e táteis de intersubjetividade que caracterizam a experiência dos bebês que estão quase constantemente nos braços de sua mãe. Para esses bebês, "a interação não tem os picos de excitação emocional vistos nas díades europeias e estadunidenses" (KÄRTNER; HOLODYNSKI; WÖRMANN, 2013, p. 86), mas também não são colocados em cadeiras de bebê, berços ou carrinhos. Ser repetidamente trazido ao colo e colocado no chão pode acelerar a capacidade do bebê de distinguir um sentido de si (mães alemãs esperam ver sorrisos sociais aos 2 meses, enquanto as mães Nso esperam isso aos 7 meses, em média), mas nem todas as culturas reconheceriam isso como algo a ser desejado ou ativamente encorajado.

Nossa história cultural tem celebrado heróis, campeóes e gênios, muitas vezes negligenciando o apoio que esses indivíduos excepcionais receberam de suas comunidades (JOHN-STEINER, 2000). Preferimos nos concentrar no que destaca nossos indivíduos mais ilustres, em vez de reconhecer suas conexóes, suas raízes nos grupos sociais que os apoiam. Frente a essa circunstância cultural, estamos mais propensos a pensar no "eu" como emergindo, ou mesmo fugindo, do "nós", mas também é possível pensar o proto-nós como sendo uma imagem holográfica. Se o holograma for quebrado, cada fragmento retém toda a imagem, assim como cada "indivíduo" retém todo o proto-nós. À medida que uma identidade pessoal surge, ela leva as suas origens sociais.

Para compreender os processos que nos permitem desenvolver identidades que são, ao mesmo tempo, pessoal/individual e pública/social, devemos focar não no conceito altamente agencial da atividade, mas sim no conceito primordialmente social da interação. Vou argumentar que os bebês são sensíveis a variaçôes sutis na experiência de interação tal como é sentida por eles bem antes de aprenderem a fazer o corte agencial entre si mesmo, como agente, e o outro, como objeto.

Colwyn Trevarthen e Penelope Hubley (1979) cunharam o termo Intersubjetividade Primária para identificar as características especiais da forma de interação "pura", sem tema definido, que caracteriza os primeiros intercâmbios entre cuidadores principais (na maioria das vezes as mães) e bebês muito pequenininhos. Os 
autores argumentaram que o fluxo de atenção e de possibilidades entre a mãe e o bebê proporciona condiçôes ideais para sincronizar sua interação, melhorando progressivamente o seu "ajuste" de modo que cada um é cada vez mais capaz de antecipar as respostas do outro e de desfrutar da sensação do conforto da familiaridade. Do ponto de vista de um ambiente cultural autônomo, podemos ser propensos a entender intersubjetividade primária como uma sequência de "turnos" imitativos assumidos por uma máe individual e um bebê individual; como um bastáo que alterna das mãos de um para as do outro - movimento por meio do qual a interação é conduzida. Mas se pudermos adotar o ponto de vista de um ambiente cultural mais relacional, talvez possamos ver esse processo como um fluxo mais contínuo de açáo mútua, como o contato físico quase constante entre mães Nso ou Gusii e seus bebês.

Embora seja difícil argumentar que os bebês de 2 meses de idade estejam conscientes das diferenças entre suas ações e as de seus parceiros de interação, é perfeitamente possível que eles sejam capazes de perceber a qualidade relacional de uma interaçáo e de discriminar entre trocas cuidadosamente co-reguladas e ajustadas com um parceiro familiar e interaçôes mais estranhas e desajeitadas com alguém que os conhece menos (e que eles conhecem menos). Steven Mithen (2005) sugeriu que a filogenia da comunicação humana começou com um compartilhamento de afeto mais musical antes que as linguagens simbólicas evoluíssem, e Marcel Kinsbourne (2005) descreveu este "estar juntos" como "balbucio imitativo" como quando o bebê e a educadora desenvolvem um padrão rítmico e alternado de sons e pausas: "Pode ser que o possível papel emocional do balbucio imitativo tenha até precedido sua função comunicativa na evolução humana" (KINSBOURNE, 2005, p. 170).

Quando as interaçôes precoces são vistas como açóes compartilhadas mutuamente provocativas é possível entender o que, de outra forma, pareceriam ser manifestaçôes precoces das emoçôes complexas sociais de "orgulho" e "vergonha". Reddy (2000) descreve exemplos de crianças pequenininhas (a partir de 2 meses de idade) respondendo à atenção com um padrão de comportamento característico de "timidez" - sorrindo enquanto se vira para o outro lado. É evidente que esses bebês são muito pequeninhos para terem desenvolvido a "autoconsciência" necessária para que experimentem vergonha, mas o seu comportamento faz todo o sentido quando é entendido como um meio de regular o nível de excitação associada à interaçáo. Quando a interação se torna demais, os bebês simplesmente se voltam para outro lado, da mesma forma como quando a interação não é animada o suficiente, eles podem "exibir-se" para aumentar o nível de atenção. Essas respostas são fundamentalmente sociais, porque elas afetam tanto a criança (virar-se reduz o impacto sensorial de interação) quanto o adulto (o movimento da criança serve como um sinal para modificar o nível de interação). 
Uma vez que o parceiro mais velho nesse tipo de interação já é iniciado na cultura, equipado com expectativas sobre como as pessoas e os bebês, em particular, podem e devem se comportar, o espaço compartilhado que esse parceiro ajuda a moldar é moldado ele próprio por geraçôes de interaçôes prévias. O que a mãe percebe nas açôes, gestos e vocalizaçôes do seu bebê é emoldurado por aquilo que vale a pena notar em sua cultura; e ela não pode evitar a direção seletiva e pedagógica da interação. Como Kaye (1979, p. 199) observou: "Quando a mãe imita, é muito mais que uma imitação de seu bebê - ela o tira de onde ele está e o leva na direção da expectativa que tem para ele". No entanto, a expectativa não é exatamente sua, e ela talvez não esteja imitando tanto quanto se entende com seu bebê, mas porque suas percepçóes estấo sintonizadas com sua cultura, ela só pode se envolver com seu bebê COMO SE ele fosse um parceiro de comunicação competente, o que cria uma zona de desenvolvimento próximo e estabelece uma situação social de desenvolvimento:

A situaçáo social do desenvolvimento [...] determina total e completamente as formas e o caminho ao longo do qual a criança vai adquirir características de personalidade cada vez mais novas, retirando-as da realidade social como a fonte básica de desenvolvimento, o caminho ao longo do qual o social torna-se o indivíduo. (VYGOTSKY, 1998, p. 198).

O proto-nós, que é sintonizado e co-construído nas condiçôes especiais de intersubjetividade primária, é influenciado, mas nunca totalmente determinado pelo meio cultural. O bebê recebe orientação intensiva em como pertencer, mas porque essas interações devem ser co-construídas ("nós" em vez de "eu-você"), elas são essencialmente não generalizáveis. O que "funciona” para uma criança não pode simplesmente ser reproduzido para outra, mesmo que para um irmáo. Ainda que possa ser possível identificar padróes gerais na interação mãe-bebê em diferentes grupos culturais, os bebês devem aprender a identificar os sinais mais sutis, que são característicos apenas de interaçóes com parceiros mais conhecidos.

Após alguns meses de trocas puramente relacionais de intersubjetividade primária, as crianças começam a demonstrar um crescente interesse na exploração por iniciativa própria do mundo material. Tendo desenvolvido a força que lhes permite manter o corpo na posição vertical, seja quando sentados ou quando carregados ao colo, os bebês agora descobrem que seus braços estấo muito mais disponíveis para tocar explorando e manipulando tudo o que vem à mão. Um "ensaio" ativo de padrôes de coordenação entre canais de informaçáo aferentes e eferentes (movendo e percebendo) torna o controle de suas mãos "automático" e "transparente" o suficiente para permitir que eles concentrem sua atenção sobre o que estão segurando ao invés de no processo de 
segurar. Vasu Reddy $(2000$, 2008) sugeriu que esse período de exploração particularmente ativa de objetos que podem ser apanhados, explorados e deixados de lado é precedida por um período em que a criança mostra um crescente interesse pelo que os outros pegam, seguram, manipulam e deixam de lado.

Um estudo realizado por Needham, Barrett e Peterman (2002), que envolveu colocar luvas de velcro em crianças de três meses de idade para que pudessem "pegar" objetos revestidos de velcro antes que elas fossem capazes de segurar objetos, também demonstrou que a experiência de exploraçáo a partir da iniciativa dos bebês os tornou mais propensos a notar e prestar atençáo ao que as outras pessoas pegavam e manipulavam. Se o modelo é outra pessoa ou a própria criança, parece que a interaçáo entre pessoas e objetos é o que primeiro capta o interesse da criança pelo fazer (GIBSON, 1979) - pelo que pode ser feito com as coisas. "O que as crianças descobrem não é como os objetos se comportam, mas sim como as pessoas se comportam com os objetos (o uso instrumental cultural desses objetos)" (PERINAT; SADURNI, 1999, p. $55)$.

Segurar algo não é, talvez, um processo simples e biológico de se envolver diretamente com um mundo objetivo; ao invés disso, até mesmo essa forma aparentemente fundamental de exploração está enraizada em ações sociais observadas e o que é "pegar algo" para um bebê é, no fundo, fortemente influenciado por teias de convençôes sociais. Em algumas famílias, as crianças sempre têm brinquedos ao seu alcance ou pendurados sobre elas; em outras, as crianças exploram os corpos, cabelos, roupas e adornos dos cuidadores que as carregam. Pegar e deixar de lado objetos (incluindo os próprios bebês) pode ser visto como manifestaçóes fundamentais da forma como as pessoas se interessam pelas coisas, sequencialmente ou coletivamente, e como elas mudam sua atenção de uma coisa para outra. Quando as crianças são elas próprias capazes de controlar o início e o término de seu interesse por objetos, pegandoos e deixando-os (geralmente sem a ajuda de luvas de velcro!), elas experimentam o que se sente ao prestar atenção em algo sem o apoio da interação com outra pessoa. Mas os bebês ainda compartilham o processo de atribuir sentido, de traduzir as informaçóes sensoriais em perezhivanie ${ }^{2}$.

$\mathrm{Na}$ segunda metade do seu primeiro ano, os bebês começam a "terceirizar" o trabalho de atribuir sentido aos objetos e situaçóes desconhecidas, monitorando as respostas de outras pessoas. Se um cuidador familiar se mostra confortável, à vontade ou feliz com um novo objeto ou evento, a criança tem mais chances de se aproximar e explorá-lo. Embora possa ser tentador ver essa referência social como evidência de consciência do bebê sobre diferenças entre "o que EU sei" e "o que VOCÊ sabe", tal consciência não é de fato necessária. $\mathrm{O}$ referenciamento social pode, no entanto, 
contribuir para a capacidade da criança de diferenciar entre pessoas mais e menos conhecidas, pois cuidadores familiares podem ser "lidos" mais facilmente e com mais precisão. "Estranhos" oferecem menos apoio no processamento de situaçóes sociais complexas, o que pode contribuir para o desenvolvimento de "ansiedade em relaçáo a estranhos" nesse período da vida.

Um marco de desenvolvimento importante na co-construção da autoconsciência vem com a intersubjetividade secundária (TREVARTHEN, 1978), a capacidade de se engajar em relaçôes triádicas (HOBSON, 2002), que envolvem a criança, outra pessoa e um foco comum de atenção. Assim como o referenciamento social, a intersubjetividade secundária não exige que a criança seja consciente de uma distinçáo entre o seu próprio ponto de vista e o ponto de vista da outra pessoa; apenas exige que ela seja capaz de reconhecer quando a atenção é coordenada. Carpenter e Liebal (2005) destacaram o forte efeito positivo que é frequentemente associado ao reconhecimento mútuo de que duas pessoas estáo compartilhando a atençáo em alguma coisa. Quando uma criança é capaz de captar a atenção de alguém e dirigi-la (geralmente pelo olhar) a um objeto ou evento e a outra pessoa, em seguida, junta-se à criança, no que Carpenter e Liebal (2005) descrevem como um "olhar compartilhado", ambos geralmente vão também compartilham um sorriso ou outros sinais de prazer. Essa associaçáo de recompensa afetiva com o compartilhamento da atençáo reflete o duplo valor desse tipo de interação. Assim como a prática e a habilidade tornaram "transparentes" os movimentos das mãos do bebê, permitindo-lhe concentrar a atençáo sobre o que ele estava segurando, da mesma forma, a criança é capaz de separar o seu próprio interesse em um objeto, permitindo-lhe se concentrar sobre a atenção da outra pessoa sobre o mesmo. A atenção para com a atenção de outra pessoa serve para reforçar o conhecimento compartilhado sobre como "nós" nos sentimos sobre esse objeto, mas também permite que a criança perceba formas pelas quais esta outra pessoa é, ao mesmo tempo, semelhante e diferente de outros outros.

Para um bebê, a tarefa de diferenciar diferentes "vocês" do proto-nós tanto antecede como contribui para a tarefa mais exigente de fazer o corte entre "nós" e "eu". Reddy (2008) descreve estudos de Fivaz-Depeursinge e colegas, na Suíça, e de Jacqueline Nadel e colegas, em Paris, que demonstraram que crianças com menos de seis meses de idade - e mesmo as de três meses - envolvem-se em uma forma de relaçáo triádica que antecede as interaçôes "eu-objeto-outro" associadas com a intersubjetividade secundária. Quando a "terceira ponta” da tríade não é um objeto, mas outra pessoa, normalmente o outro progenitor, mesmo as crianças muito pequenininhas podem participar de interaçôes triádicas "pessoa-pessoa-pessoa", alternando o olhar entre seus parceiros e demonstrando coordenação de afeto: 
Por exemplo, uma criança começaria pela mãe, olhando-a intensamente, sorrindo e balbuciando; ela, então, se voltaria para o pai, mantendo seu sorriso e gesto vocal. Ou, em um momento difícil, seu rosto se entristeceria, e ela se voltaria com a mesma expressão para o outro progenitor. (REDDY, 2008, p. 111).

Para a criança de três meses de idade, esse tipo de interação proporciona oportunidades para sentir a diferença entre interaçóes com parceiros mais e menos conhecidos, entre aqueles com os quais as experiências íntimas da intersubjetividade primária construíram uma espécie de hiper-familiaridade e aqueles que ainda que sejam conhecidos não são tão conhecidos. Desse ponto de vista, a intersubjetividade elementar serve tanto para sincronizar as interaçôes como para acentuar as diferenças entre pessoas mais e menos conhecidas; entre o conforto e segurança da "casa" e a novidade e emoção do "fora dela". As experiências posteriores de interaçôes triádicas "pessoa-objeto-pessoa" permitem que os bebês expandam essa consciência de diferentes "você" dentro do proto-nós, permitindo-lhes explorar a peculiaridade das respostas a objetos e eventos das diferentes pessoas.

Repacholi e Gopnik (1997) demonstraram que as crianças com 18 meses de idade (mas não as de 14 meses) foram capazes de reconhecer que outra pessoa pode ter preferências diferentes dos gostos da própria criança, por exemplo, que um adulto pode preferir brócolis cru a bolacha. Eu acredito que esse estudo mostra como as crianças começam a associar aspectos "visíveis" de suas interaçôes com os diferentes significados que diferentes pessoas atribuem aos objetos e eventos que eles experimentaram juntos em períodos de atenção conjunta. Para o bebê, o significado de um objeto ou evento é nada mais nada menos do que a relação entre o objeto/evento e uma pessoa em particular. O significado será generalizado mais tarde de modo que se torna possível falar sobre o significado de um objeto/evento, mas inicialmente a peculiaridade das relaçôes de diferentes pessoas com as coisas fornece informaçôes valiosas sobre como as pessoas podem ser diferentes.

É claro que os bebês são, ao mesmo tempo, sujeitos e objetos em suas interações com os outros e sua crescente consciência do que diferentes coisas significam para diferentes pessoas incluirá a consciência do que eles significam para os outros. A primeira experiência do "eu", pela criança, vem das maneiras como as outras pessoas interagem diferentemente ao interagir com esse "eu". O desenvolvimento da identidade é, portanto, um exemplo do processo de internalização que Vygotsky (1997, p. 106) identificou em sua lei genética geral: 
Podemos formular a lei genética geral do desenvolvimento cultural da seguinte forma: toda função no desenvolvimento cultural da criança aparece em cena duas vezes, em dois planos; primeiro, no social, então no psicológico; primeiro, entre as pessoas como uma categoria interpsíquica e, então, dentro da criança como uma categoria intrapsíquica.

A maneira como entendemos o social tem um impacto direto, portanto, em como entendemos o psicológico. Se pensarmos as interaçôes em termos da passagem sequencial de blocos de informação de um participante para o outro, então vamos também pensar sobre nossos processos mentais de forma similar. Se, por outro lado, pensamos as interaçôes em termos de um fluxo co-regulado de informaçáo, simultaneamente influenciado por todos os participantes, isto pode permitir-nos pensar sobre o ato de pensar reconhecendo mais plenamente a contribuição de múltiplos processos, incluindo aqueles em relaçáo aos quais podemos não ser conscientes.

Nossa experiência de outras pessoas (e, por extensão, de nós mesmos) inclui a nossa percepção consciente de suas características distintivas, mas também a nossa percepção menos consciente de uma resposta fenomenológica rica e complexa para elas. Quando interagimos com outra pessoa nos tornamos influenciadas por elas, ajustando nossa fala, sotaque, gestos, proximidade e a excitação afetiva para sintonizar o nosso eu com o eu delas. As nossas memórias desses ajustamentos se tornam parte do nosso conhecimento de outras pessoas, mas elas também se tornam parte de nosso conhecimento sobre nós mesmos.

O tipo sutil de saber que somos capazes de produzir a partir da atenção compartilhada é um exemplo do que Shotter (2012, p. 3) descreveu como "pensamento compartilhado", "um saber que tem a ver com a participação de alguém em uma situaçáo, com o 'lugar' de alguém na situação e com a forma como alguém pode 'continuar' a fazer seu papel nessa situação". Esse tipo de saber não pode ser alcançado "de fora", lendo ou ouvindo de alguém; ele só pode ser adquirido dentro de formas específicas de interação social. É por esta razão que as amizades precisam ser mantidas por um envolvimento regular de atenção conjunta - fazer as coisas juntos e, especialmente, envolver-se em uma conversa divertida. As mudanças e a variedade de atitudes que as interaçôes lúdicas provocam permite que os participantes "percebam" mudanças sutis no fluxo de informaçôes, reorganizando seu modelo internalizado de como se pode esperar que as outras pessoas respondam. Com a introdução de um espaço (ou um corte) entre o nosso eu co-construído e o nosso "pensar compartilhado" co-construído sobre nossas interações com os outros, desenvolvemos tanto a nossa 
capacidade de nos destacarmos como nossa capacidade de nos adaptar - ao conhecer o que é próprio dos outros, chegamos a nos conhecer e, conhecendo a nós mesmos, somos mais capazes de perceber tanto as diferenças como as semelhanças dos outros.

Berger e Luckman (1966) introduziram uma distinção entre socialização primária, o processo pelo qual encontramos nosso lugar (e nossa identidade) no interior do proto-nós da nossa família imediata, e socialização secundária, os processos posteriores pelos quais descobrimos o lugar do nosso proto-nós no interior de uma variedade de "nós" ampliado, mesossistemas ou ambientes culturais. A criança que encontrou o seu lugar dentro de sua família e começou a envolver-se em interaçóes lúdicas com crianças de outras famílias descobre como outros reagem a alguns aspectos de sua cultura "doméstica" - aprendendo simultaneamente sobre outras famílias e sobre sua própria, de forma muito similar à maneira como ela aprendeu sobre outras identidades e sobre a sua própria. Em uma escala ainda maior, comparaçóes interculturais, como as mencionadas acima (LEVINE et al., 1994; Konner, 2010; Kartner et al., 2013), permitem aos pesquisadores aprender tanto sobre outras culturas como sobre a sua própria.

Estas diferentes escalas de identidade compartilhada nos lembram que cada pessoa com quem interagimos foi co-construída na interação com outros que foram coconstruídos em outras interaçóes com outros outros. Quando, portanto, internalizamos o "compartilhamento" de nossas interaçóes com outras pessoas, estamos absorvendo a complexidade fractal de co-construçóes repetidamente tecidas de identidades.

Quando entendemos o desenvolvimento da identidade tanto como uma separação do "eu" em relação ao "nós" quanto como uma internalização de padrôes familiares de interação (diálogo interno, jogo e argumento), a insistência de Shotter (2012) sobre a fluidez das fronteiras entre sujeito/agente e objeto parece inteiramente apropriada. Se os processos intrapsíquicos são versôes internalizadas de interaçôes interpsíquicas, a distinção entre "nós" e "eu" pode não ser táo clara como tendemos a pensar. Na verdade, o desejo de separação metódica pode ser ele próprio produto de um ambiente cultural específico. Ao explicar a importância do pensar compartilhado, Shotter (2012) cita a observação de Wittgenstein (1953, p. 107 apud SHOTTER, 2012, p. 6) de que explorar relaçóes abstratas entre ideias descontextualizadas é como caminhar no gelo "onde não há atrito e, assim, num certo sentido, as condições são ideais, mas também, por isso, não somos capazes de andar. Queremos andar: por isso precisamos de atrito. Voltemos para o terreno áspero".

Shotter (2012)sugere que a força do "pensar compartilhado", a complexidade da informação essencialmente humana que somos capazes de perceber na interação 
social, é o que torna possível para nós "continuarmos" quando lidamos com a instabilidade de ideias metódicas.

A preferência por organização também pode levar-nos a buscar conclusóes bem arrumadas, para tentar identificar que tipo de ambientes culturais, etnoteorias sobre famílias ou práticas parentais são "melhores" para as crianças pequenas ou para realizar estudos de investigação em grande escala para identificar "o que funciona" com a finalidade de, em seguida, expandir essa prática bem sucedida, independentemente das necessidades específicas de determinados contextos. Pode ser que alguns tipos de cuidado infantil possam ser associados com o desenvolvimento mais rápido das qualidades que consideramos vantajosas. Bebês que são acolhidos ao colo e devolvidos ao chão, com momentos intensos de interação face a face, podem demonstrar sorrisos sociais mais cedo do que os bebês que são carregados a maior parte do tempo e que experimentam formas mais calmas de interação, mas isso não significa que os bebês mais quietos estão atrasados no desenvolvimento de seu sorriso social. Crianças que são cuidadas por diferentes cuidadoras podem desenvolver mais rapidamente a capacidade de se comunicar por meio da linguagem oral em meios mais públicos do que as crianças que passam mais tempo com pessoas com quem estão familiarizadas e com as quais outras formas de comunicação são eficazes. Mas isso não quer dizer que a criança menos verbal tenha um atraso no desenvolvimento da fala.

É tentador evitar tais julgamentos dizendo que os melhores tipos de experiências para um bebê são apenas aquelas que lhe permitam participar efetivamente no meio cultural em que ele vai viver, mas isso pressupóe que as pessoas acabem vivendo em uma única cultura que é essencialmente a mesma na qual elas crescem. As culturas variam em todos os níveis possíveis, e os diferentes padróes de relaçóes entre "nós" e "eu" (e "você" e “eles”) que elas apoiam também são fortemente variáveis. Mesmo no mais íntimo das famílias, a perezhivanie de cada pessoa será, inevitavelmente, um pouco diferente. Essas diferenças incluem: fatores intrapessoais que derivam da forma singular e das dinâmicas de corpos distintos (por exemplo, crianças quietas e crianças curiosas); relaçóes interpessoais com (e entre) outros membros da família (primogênito e segundo filho e mudança nas relaçóes entre os pais com o passar do tempo); e mudanças no contexto sócio-histórico à medida que as relaçôes alternam entre microssistemas e macrossistemas (por exemplo, se o emprego dos pais é afetado por mudanças nas políticas ou na economia).

Nossas identidades são hoje raramente uma simples questão de pertencer a um grupo social coerente, coeso, que define todos os aspectos das nossas relaçóes, valores e julgamentos sociais internalizados - somos mais propensos a nos mover entre círculos de pertença sobrepostos, como família, comunidade, trabalho, política, atividades de 
lazer - e o proto-nós em que primeiro descobrimos nossa "própria" identidade pode ser apenas um, e não necessariamente o mais valorizado ou central, de diferentes conjuntos de relaçôes e valores. É a irredutível complexidade de nossos relacionamentos com outras pessoas que torna a interação social gratificante e, ao invés de tentar identificar o tipo de experiências de infância que irá garantir os melhores resultados de desenvolvimento para todas as crianças, talvez devêssemos desejar incentivar uma maior diversidade de oportunidades de interação entre "eus" individuais e entre os "nós" sociais de outras culturas, tradiçôes, disciplinas e crenças. Não basta simplesmente saber sobre as pessoas que veem as coisas de forma diferente de nós. Isso é caminhar no gelo. Apenas quando nos envolvemos com outras pessoas na vida social podemos perceber as sutilezas de como elas moldam o fluxo de informação, o que as coisas significam para elas e como elas nos veem. É nessa partilha de "pensar compartilhadamente" que somos capazes de encontrar não apenas outras mentes, mas outros eus.

\section{Notas}

${ }^{1}$ Em russo no original (N.T.).

${ }^{2}$ Em russo no original. Em português, pode ser traduzido como experiência emocional (N.T.).

\section{REFERÊNCIAS}

BERGER, Peter. L; LUCKMANN, Thomas. The social construction of reality: a treatise in the sociology of knowledge. Garden City, NY: Anchor Books, 1966.

BRONFENBRENNER, Urie. The ecology of human development: experiments by nature and design. Cambridge, MA: Harvard University Press, 1979.

CARPENTER, Malinda; LIEBAL, Katja. Joint attention, communication and knowing together in infancy. In: SEEMANN, Alex (Org.). Joint attention: new developments in psychology, philosophy of mind, and social neuroscience. Cambridge, MA: MIT Press, 2011. p. 159-81.

ELIAS, Norbert. The civilizing process: the development of manners. Oxford: Blackwell, 1978.

GIBSON, James J. The ecological approach to visual perception. Boston: Houghton Mifflin, 1979. 
HOBSON, Peter. The cradle of thought: exploring the origins of thinking. London: Macmillan, 2002.

HOLODYNSKI, Manfred; FREIDLMEIER, Wolfgang. Emotions: development and regulation. New York: Springer, 2006.

JOHN-STEINER, Vera. Creative collaboration. Oxford: Oxford University Press, 2000.

KAYE, Kenneth. Thickening thin data: the maternal role in developing communication and language. In: BULLOWA, Margaret (Org.). Before speech: the beginning of interpersonal communication. Cambridge: Cambridge University Press, 1979. p. 191-206.

KÄRTNER, Joscha;, HOLODYNSKI, Manfred; WÖRMANN Viktoriya. Parental ethnotheories, social practice and the culture-specific development of social smiling in infants, Mind, Culture, and Activity, v. 20, n. 1, p. 79-95, 2013.

KINSBOURNE, Marcel. Imitation as entrainment: brain mechanisms and social consequences. In: HURLEY, Susan; CHATER, Nick (Org.). Perspectives on imitation: from neuroscience to social science. Cambridge, MA: MIT Press, 2005. p. 163-172. v. 2.

KONNER, Melvin. The evolution of childhood: relationships, emotion, mind. Cambridge, MA: Harvard University Press, 2010.

LEVINE, Robert A. et al. Child care and culture: lessons from Africa. New York, NY: Cambridge University Press, 1994.

MITHEN, Steven. The singing neanderthals: the origins of music, language, mind and body. London: Weidenfeld and Nicholson, 2005.

NEEDHAM, Amy; BARRETT, Tracy; PETERMAN, Karen. A pick-me-up for infants' exploratory skills: early simulated experiences reaching for objects using 'sticky mittens' enhances young infants' object exploration skills. Infant Behavior and Development, v. 25, p. 279-295, 2002.

PERINAT, Adolfo; SADURNÍ, Marta. The ontogenesis of meaning: an interactional approach, Mind, Culture and Activity, v. 6, n. 1, p. 53-76, 1999.

REPACHOLI, Betty; GOPNIK, Alison. Early reasoning about desires: evidence from 14 and 18 month-olds. Developmental Psychology, v. 33, n. 1, p. 12-21, 1997. REDDY, Vasu. Coyness in early infancy. Developmental Science, v. 3, n. 2. p. 186-192, 2000 . 
REDDY, Vasu. How infants know minds. Cambridge, MA: Harvard University Press, 2008.

SHOTTER, John. More than cool reason: "withness-thinking" or "systemic thinking and thinking about systems". International Journal of Collaborative Practices, v. 3, n. 1, p. 1-13, 2012.

SHOTTER, John. Agential realism, social constructionism, and our living relations to our surroundings: sensing similarities rather than seeing patterns. Theory \& Psychology, 7 jan. 2014.

TREVARTHEN, Colwyn; HUBLEY, Penelope. Secondary intersubjectivity: confidence, confiding and acts of meaning in the first year. In: LOCK, Andrew (Org.) Action, gesture and symbol: the emergence of language. London: Academic Press, 1978. p. 183-229.

TREVARTHEN, Colwyn. Communication and cooperation in early infancy: a description of primary intersubjectivity. In: BULLOWA, Margaret (Org.). Before speech: the beginning of interpersonal communication. Cambridge: Cambridge University Press, 1979. p. 321-347.

VYGOTSKY, Lev S. The history of the development of the higher mental functions. New York: Plenum, 1997. (The collected works of L. S. Vygotsky, v. 4).

VYGOTSKY, Lev, S. Child Psychology. New York: Springer,1998. (The collected works of L. S. Vygotsky, v. 5).

ZEEDYK M. Suzanne. From intersubjectivity to subjectivity: the transformative roles of emotional intimacy and imitation. Infant and Child Development, v. 15, p. 321-344, 2006. 


\section{From us to you to me: the coconstruction of identity in early interactions}

\begin{abstract}
From a cultural historical perspective, the relationship between the interpsychic processes of 'public' social interaction and the intrapsychic processes of 'private' thought are complex and reciprocal. While we can say that identity emerges out of a primary 'we' state, we can also argue that we are only able to develop self-awareness because we internalize forms of interaction which are first experienced between people. In this paper we will consider how the co-construction of identity can be understood in terms of a developing ability to participate in the flow of information afforded by social interactions. We argue that social interactions provide opportunities to learn much more about other people (and about ourselves) than is accessible to our conscious awareness.
\end{abstract}

Keywords: Childhood. Identity. Internalisation.
De nosotros para vos y para mí: la co-construción de la identidad en las interacciones iniciales

\section{Resumen}

Desde una perspectiva histórico-cultural, la relación entre los procesos inter-psíquicos de la interacción social "pública" y los procesos intra-psíquicos del pensamiento "privado" es compleja y recíproca. Si bien podemos decir que la identidad surge a partir de un estado primario de un 'nosotros', podemos argumentar también que sólo somos capaces de desarrollar la auto-conciencia porque interiorizamos formas de interacción que primero son experimentadas entre personas. Será considerado en este artículo cómo la coconstrucción de la identidad puede ser entendida en términos de la capacidad de participar en el desarrollo del flujo de la información proporcionada por las interacciones sociales. Voy a argumentar que las interacciones sociales ofrecen oportunidades para aprender mucho más acerca de otras personas (y de nosotros mismos) de aquello que es accesible a nuestra percepción consciente.

Palabras claves: Infancia. Identidad. Teoria histórico-cultural. 


\section{Rod Parker-Rees}

E-mail: rod.parker-rees@plymouth.ac.uk

\section{Suely Amaral Mello}

E-mail: suepedro@terra.com.br

Recebido em: 5/5/2014 Aprovado em: 26/7/2014 